\title{
KIT NP_000213.1:p.L813P
}

National Cancer Institute

\section{Source}

National Cancer Institute. KIT NP 000213.1:p.L813P. NCI Thesaurus. Code C155690.

A change in the amino acid residue at position 813 in the mast/stem cell growth factor receptor Kit protein where leucine has been replaced by proline. 